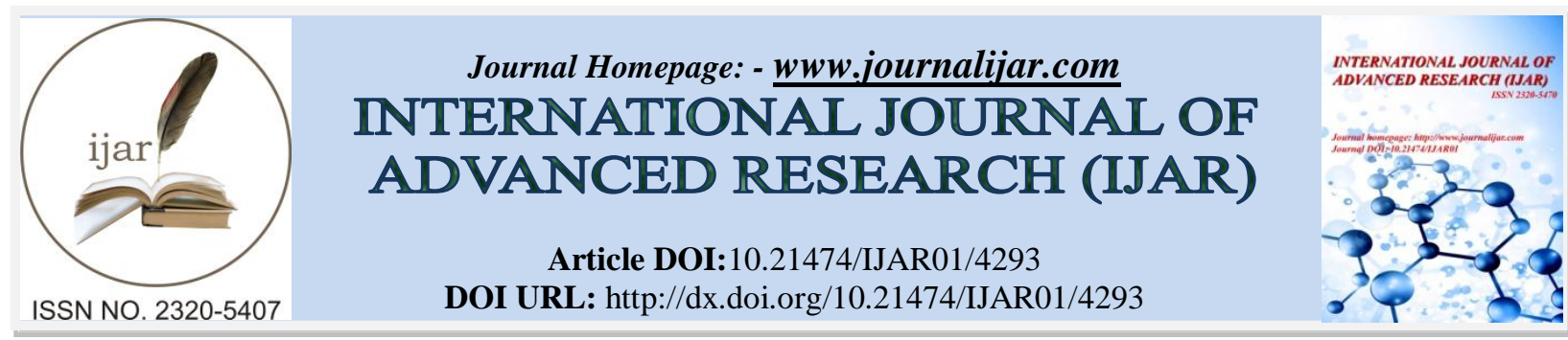

RESEARCH ARTICLE

\title{
HYPERHOMOCYSTINEMIA IN EPILEPTIC PATIENTS: THE ROLE OF THFR POLYMORPHISM AND ANTIEPILEPTIC DRUGS.
}

\author{
Nesma A.M. Ghonimi ${ }^{1}$, Mohammed E. Mahdy ${ }^{1}$, Tamer S. Elserafy ${ }^{1}$, Nora S. Abdelrahman ${ }^{2}$ and Bothina M. \\ Ramadan ${ }^{1}$. \\ 1. Neurology department, Faculty of medicine, zagazig university, Egypt. \\ 2. Clinical pathology department, Faculty of medicine, zagazig university, Egypt.
}

\section{Manuscript Info}

Manuscript History

Received: 26 March 2017

Final Accepted: 27 April 2017

Published: May 2017

\section{Abstract}

Hyperhomocystinemia despite can be seen in small perecentage of normal population but associated with increased vascular diseases in epileptics, hyperhomocystinemia in epileptic patients was supposed to develop primarily from a complex interplay between the chronic intake of enzyme inducing AEDs and genetically determined mutations of MTHFR. Ninety two patients with epilepsy between the ages of 18 and 40 years consented to participate in the study in order to study analyses the effect of a C677T polymorphism of MTHFR and AEDs on tHcy levels in patients with epilepsy treated for at least 6 months with monotherapy including the traditional and newer AEDs.

Copy Right, IJAR, 2017,. All rights reserved.

\section{Introduction:-}

Homocysteine (Hcy) which is a sulfur-amino acid, considered as an intermediate product of methionine metabolism and is normally at plasma total $(\mathrm{t})$ concentrations $<15 \mathrm{umol} / \mathrm{L}$. Its higher values more than $15 \mathrm{umol} / \mathrm{L}$ i.e. hyperhomocysteinemia are considered abnormal and this can be seen in about $5 \%$ of the general population. Higher percentages, from 10-20\%, are observed in epileptic patients Hcy(Caccamo et al., 2004; Belcastro et al., 2007).

Hyperhomocysteinemia is associated with increased vascular disease risk in epileptics (Williams and Schalinske, 2010). Furthermore, it was shown to enhance seizure activity in those patients (Baldelli et al., 2010).

There are conflicting data about the role of methylene tetrahydro folate reductase (MTHFR) polymorphisms (particularly the C677T and A1298C) as determining factor of high total homocysteine plasma (tHcy) levels in epileptic patients (Ono et al., 2002). MTHFR is a key enzyme in the production of 5-methyltetrahydrofolate (a major circulating form of folate in human), which is the primary methyl donor for Hcyremethylation to methionine. The C677T mutation of the MTHFR gene decreases the activity of this enzyme leading to decreased folate levels in serum and subsequent accumulation of homocystien(Jacques et al.,1996).

A relationship between increased tHcy levels and antiepileptic drugs (AEDS) adminstration, has also been recognized in the last decade (Sener et al.,2006; Kurul et al.,2007) . Antiepileptic drugs, in fact, deplete folate and other B vitamins (necessary cofactors in the metabolic pathways of Hcy). So, hyperhomocystinemia in epileptic patients was supposed to develop primarily from a complex interplay between the chronic intake of enzyme inducing AEDs and genetically determined mutations of MTHFR (Caccamo et al., 2004; Belcastro et al., 2007). 
The present study analyses the effect of a C677T polymorphism of MTHFR and AEDs on tHcy levels in patients with epilepsy treated for at least 6 months with monotherapy including the traditional and newer AEDs.

\section{Subjects And Method:-}

Subjects were consecutively recruited from epileptic patients under treatment by AEDS monotherapy (including new and traditional) at Zagazig university hospitals and out-patient clinic, from August 2016 through Feb 2017. Ninety two patients with epilepsy between the ages of 18 and 40 years consented to participate in the study. We excluded those with neurometabolic or systemic diseases such as thyroid or renal dysfunction, chronic therapy with drugs other than AEDs and current or previous treatment with folic acid and/or other vitamins. Compliance and adherence to therapy were assessed using Morisky medication adherence scale.

Ninety two healthy control who had no clinical and/or laboratory evidence of metabolic and/or endocrine diseases were included. Controls were recruited from outpatients of the Neurology Department, Zagazig University. These subjects had been referred for non-epileptic problems e.g. episodic headache, minor head trauma, and dizziness. Exclusion criteria were identical to those of the patient group. Multivitamin users were also excluded from the study.

All patients and controls underwent the following examinations: complete blood count, liver and kidney function tests and serum levels of folic acid and tHcy. DNA was extracted from peripheral blood using the QIAamp DNA Blood Mini Kit (Qiagen, Hilden, Germany) following the manufacturer's recommendations and then stored at $-20^{\circ} \mathrm{C}$.

After blood samples were obtained, plasma was immediately separated by centrifugation at $1000 \mathrm{~g}$ for $15 \mathrm{~min}$. Blood samples were immediately processed in order to prevent artefactual variations of tHcy, due to the products of in vitro erythrocyte metabolism. Samples were stored at $-20^{\circ} \mathrm{C}$ until analysis. Plasma total levels of Hcy and folate were assessed by use of commercially available kit for Human Homocysteine(HCY)ELISA kit (Competitive ELISA) (MyBioSource, Inc., San Diego,USA), Human Folic Acid (FA) ELISA Kit (MyBioSource, Inc., San Diego,USA) respectively. Plasma tHcy concentrations were considered elevated when they exceeded $15 \mathrm{umol} / \mathrm{L}$, and $<4 \mathrm{ng} / \mathrm{mL}$ folate. (Myers et al., 2009 ;Benoist, 2008).

Genotyping for C677T MTHFR polymorphisms was carried out on DNA extracted from white cells of freshly drawn peripheral blood samples. In each patient, isolation of DNA was performed by using the QIAamp DNA Blood Mini Kit (Qiagen, Hilden, Germany) following the manufacturer's recommendations.

The MTHFR C677T(rs1801133) mutation was detected using the ABI StepOne TM Real Time PCR System (Applied Biosystems) and analyzed using Step one software v2.3 (Applied Biosystems), using the TaqMan assay. The final volume for each reaction was $20 \mu \mathrm{L}$, containing $10 \mu \mathrm{LTaqMan}$ Genotyping Master Mix, 1.0 $\mu \mathrm{LTaqMan}$ probes mix, $20 \mathrm{ng}$ genomic DNA and reaching the final volume with RNAse- free water. PCR temperature profile consisting of denaturation at $95^{\circ} \mathrm{C}$ for 10 minutes followed by 40 cycles of denaturation at $95^{\circ} \mathrm{C}$ for 15 seconds and then annealing and elongation at $65^{\circ} \mathrm{C}$ for 1 minute.

\section{Statistical Analysis:-}

Comparison of discrete variables (sex, MTHFR C677Tgenotype distribution) was made using the chi square test. Student's t-test for unpaired data was used to compare tHcy concentrations of patients and controls while folate levels were investigated using the Mann-Whitney. ANOVA $F$-test was used to compare tHcy levels among the three MTHFR genotypes in patients and controls. Kruskal-Wallis test was implemented to explore the variation of plasma folate levels across the three MTHFR genotypes in patients and controls. Multiple logistic regression analysis was used to analyze factors of influence on tHcy concentrations, odds ratio was calculated for each variable. SPSS (Statistical Package for Social Science) version 18 was used for statistical analysis (SPSS, Chicago). $\mathrm{p}<0.05$ values were considered significant.

\section{Results:-}

In table 1 we summarized demographic and clinical characteristics of the study subjects. A total of 92 epileptic patients (53 male, 39 female) with mean age ( $\mathbf{3 0 . 5} \pm \mathbf{8 . 5}$ years $)$ were included in the study; in addition to 92 healthy age and sex matched controls. All patients were on monotherapy, the AEDs used in the study group were as follows:phenytoin $(n=11)$, carbamazepine $(n=17)$, valproic acid $(n=20)$, topiramate $(n=10)$, oxcarbazepin $(n=$ 14), lamotrigin $(n=10)$ and levetricetam $(n=10)$. Mean tHcy values were significantly higher in patients than in 
controls $(17.3 \pm 3.2$ vs $6.9 \pm 2.2 ; \mathrm{p}<0.001)$, while folic acid concentrations were significantly lower in patients than those of controls $(7.3 \pm 2.5$ vs $10.0 \pm 4.2 ; \mathrm{p}<0.001)$ and these differences remained significant even if patients and controls were grouped according to the MTHFR genotypes. Our patients showed the following distribution of MTHFR polymorphism: CT (41.3\%), CC (29.3\%), and TT (21.7\%). Of epileptic patients involved in this study, carriers of the TT677 MTHFR genotype had a significant increase in tHcy $(\mathrm{F}=280, \mathrm{p}<0.0001)$ and significant decrease in folate levels $(\mathrm{KW}=3.23, \mathrm{P}=0.04)$ ( (Table 2). Multiple logistic regression data analysis showed a significant negative correlation between folic acid serum levels and tHcy levels ( $<$ 0.001); in addition, TT677 MTHFR genotype and type of AEDs therapy, proved to be a significant risk factor for high tHcy levels in epileptic patients $(\mathrm{p}<0.001)$ (Table 3). A significant difference in plasma tHcy values was also seen across patients stratified on the basis of pharmacogenetics .Hyperhomocysteinemia was observed in patients on carbamazepine (CBZ), phenobarbital (PB), topiramate (TPM), and oxcarbazepine (OXC) therapy, especially in TT677 MTHFR genotype. Plasma tHcy levels in patients taking LTG and LEV therapy were significantly lower than those observed in the other drug groups and not significantly different from those observed in the controls and in the VPA group (figure1).

Table 1:-Clinical and Biochemical Characteristics of Epileptic Patients Receiving AEDs and Healthy Controls.

\begin{tabular}{|c|c|c|c|c|c|}
\hline Variable & $\begin{array}{r}\text { Epileptic } \\
\text { Patients } \\
(\mathbf{n}=92)\end{array}$ & $(\mathrm{n}=92)$ & Test & $\begin{array}{c}\mathbf{p} \\
\text { value }\end{array}$ & OR \\
\hline \multicolumn{6}{|l|}{ Demographic data: } \\
\hline Sex ratio (male/female) & $53 / 39$ & $51 / 41$ & $\chi^{2}=0.09$ & $0.77 \mathrm{NS}$ & 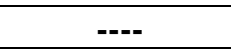 \\
\hline Age $(\mathrm{yr})$ & $30.5 \pm 8.5$ & $32.1 \pm 6.8$ & $\mathrm{t}=1.41$ & $0.16 \mathrm{NS}$ & 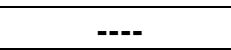 \\
\hline \multicolumn{6}{|l|}{ Clinical data: } \\
\hline Duration of epilepsy (yr) & $8.4 \pm 4.10$ & NA & -- & -.. & -..- \\
\hline $\begin{array}{l}\text { Seizure types } \\
\text { Primary generalized } \\
\text { Temporal focal } \\
\text { Extratemporal focal }\end{array}$ & $\begin{array}{l}\text { (n) } 66 \\
\text { (n) } 11 \\
\text { (n) } 15\end{array}$ & $\begin{array}{l}\text { NA } \\
\text { NA } \\
\text { NA }\end{array}$ & --- & ---- & ---- \\
\hline Duration of therapy & $6.5 \pm 2.4$ & & - & - & - \\
\hline tHcy $(\mu \mathrm{mol} / \mathrm{L})$ & $17.3 \pm 3.2$ & $6.9 \pm 2.2$ & $t=25.69$ & $<0.001 * *$ & $\cdots$ \\
\hline folate $(\mathrm{ng} / \mathrm{mL})$ & $7.3 \pm 2.5$ & $10.0 \pm 4.2$ & $M W=5.9$ & $<0.001 * *$ & $\cdots$ \\
\hline \multicolumn{6}{|l|}{ Genetic data: } \\
\hline $\begin{array}{l}\text { CC677 MTHFR genotype } \\
\text { CT677 MTHFR genotype } \\
\text { TT677 MTHFR genotype }\end{array}$ & $\begin{array}{l}27(29.3 \%) \\
32(34.8 \%) \\
33(35.9 \%)\end{array}$ & $\begin{array}{c}34(37 \%) \\
38(41.3 \%) \\
20(21.7 \%)\end{array}$ & $\begin{array}{l}\chi^{2}=1.2 \\
\chi^{2}=0.83 \\
\chi^{2}=4.48\end{array}$ & $\begin{array}{c}0.27 \text { NS } \\
0.36 \text { NS } \\
0.03 *\end{array}$ & $\begin{array}{l}1.41(0.76-2.62) \\
1.32(0.73-2.40) \\
2.01(1.05-3.87)\end{array}$ \\
\hline
\end{tabular}

t: Independent sample t test, $\chi^{2}$ : Chai square test, MW: Mann Whitney test , NA: not applicable

Table 2:-Levels of tHcy and Plasma Folate in Epileptic Patients receiving AEDs and Healthy Controls According to MTHFR Genotype:

\begin{tabular}{|c|c|c|c|c|}
\hline Genotype & $\begin{array}{l}\text { Epileptic Patients } \\
\quad(\mathrm{n}=92)\end{array}$ & $\begin{array}{l}\text { Healthy Controls } \\
\quad(\mathrm{n}=92)\end{array}$ & Test & \\
\hline $\begin{array}{l}\text { CC677 MTHFR } \\
\text { tHcy }(\mu \mathrm{mol} / \mathrm{L})\end{array}$ & $\begin{array}{c}(\mathrm{n}=27) \\
16.5 \pm 3.3 \mathrm{a}\end{array}$ & $\begin{array}{c}(\mathrm{n}=34) \\
9.7 \pm 2.2 \mathrm{c}\end{array}$ & $\begin{array}{c}\mathrm{t} \\
9.63\end{array}$ & $<0.001 * *$ \\
\hline $\begin{array}{l}\text { CT677MTHR } \\
\text { tHcy }(\mu \mathrm{mol} / \mathrm{L})\end{array}$ & $\begin{array}{c}(\mathrm{n}=32) \\
16.0 \pm 3.3 \mathrm{a}\end{array}$ & $\begin{array}{c}(\mathrm{n}=38) \\
12.9 \pm 2.3 \mathrm{c}\end{array}$ & $\begin{array}{c}t \\
4.61\end{array}$ & $<0.001 * *$ \\
\hline $\begin{array}{l}\text { TT677MTHR } \\
\text { tHcy }(\mu \mathrm{mol} / \mathrm{L})\end{array}$ & $\begin{array}{c}(\mathrm{n}=33) \\
\mathbf{3 3 . 8} \pm \mathbf{3 . 6} \mathrm{b}\end{array}$ & $\begin{array}{c}(\mathrm{n}=21) \\
15.6 \pm 3.2 \mathrm{~d}\end{array}$ & $\begin{array}{c}t \\
18.89\end{array}$ & $<0.001 * *$ \\
\hline $\mathbf{F}$ & 280 & 37.92 & & \\
\hline $\mathbf{P}$ & $<0.001 * *$ & $<0.001 * *$ & & \\
\hline $\begin{array}{l}\text { CC677 MTHFR } \\
\text { Folate }(\mathrm{ng} / \mathrm{mL})\end{array}$ & $\begin{array}{c}(n=27) \\
8.5 \pm 5.1 \text { a }\end{array}$ & $\begin{array}{c}(n=34) \\
9.0 \pm 4.9 c\end{array}$ & $\begin{array}{l}\text { MW } \\
\text { 0.40 }\end{array}$ & 0.70 NS \\
\hline $\begin{array}{l}\text { CT677MTHR } \\
\text { Folate }(\mathrm{ng} / \mathrm{mL})\end{array}$ & $\begin{array}{c}(n=32) \\
8.6 \pm 3.9 a\end{array}$ & $\begin{array}{c}(\mathrm{n}=38) \\
9.3 \pm 4.0 \mathrm{c}\end{array}$ & $\begin{array}{l}\text { MW } \\
\text { 0.47 }\end{array}$ & 0.46 NS \\
\hline $\begin{array}{l}\text { TT677MTHR } \\
\text { Folate }(\mathrm{ng} / \mathrm{mL})\end{array}$ & $\begin{array}{c}(\mathrm{n}=33) \\
6.4 \pm 4.9 \mathrm{~b}\end{array}$ & $\begin{array}{c}(\mathrm{n}=20) \\
10.1 \pm 2.3 \mathrm{c}\end{array}$ & $\begin{array}{l}\text { MW } \\
3.16\end{array}$ & $0.003 * *$ \\
\hline
\end{tabular}




\begin{tabular}{|c|c|c|c|}
\hline KW & $\mathbf{3 . 2 3}$ & $\mathbf{0 . 4 8}$ & \\
\hline P & $\mathbf{0 . 0 4} *$ & $\mathbf{0 . 6 2} \mathbf{N S}$ & \\
\hline
\end{tabular}

Values are indicated as mean \pm SD, MW:Mann Whitney test, KW: Kruskal-Wallis test ,F: ANOVA F test. Groups with different letters are statistically significant $(\mathrm{P}<0.05)$.

Table 3:- Multiple regression analysis showing the association of AEDs, TT677 genotype, vitamin status, and demographic variables with plasma tHcy

\begin{tabular}{|l|c|c|c|c|c|}
\hline & Beta & B & SE & OR & p-value \\
\hline TT677 MTHFR & $\mathbf{0 . 3 4}$ & $\mathbf{0 . 3 1}$ & $\mathbf{0 . 0 3}$ & $\mathbf{9 . 8}$ & $<0.001 * *$ \\
\hline Folate & $\mathbf{0 . 4 5}$ & $\mathbf{0 . 0 9}$ & $\mathbf{0 . 0 1}$ & $\mathbf{1 1 . 1}$ & $<0.001 * *$ \\
\hline Age & $\mathbf{0 . 0 2}$ & $\mathbf{0 . 0 0}$ & $\mathbf{0 . 0 3}$ & $\mathbf{0 . 6 0}$ & $\mathbf{0 . 5 0}$ \\
\hline Sex & $\mathbf{0 . 0 3}$ & $\mathbf{0 . 0 2}$ & $\mathbf{0 . 0 3}$ & $\mathbf{0 . 8}$ & $\mathbf{0 . 4 1}$ \\
\hline Therapy & & & & \\
\hline OXC & $\mathbf{0 . 1 0}$ & $\mathbf{0 . 1 2}$ & $\mathbf{0 . 0 5}$ & $\mathbf{2 . 3}$ & $\mathbf{0 . 0 0 2} * *$ \\
\hline TPM & $\mathbf{0 . 2 0}$ & $\mathbf{0 . 2 5}$ & $\mathbf{0 . 0 6}$ & $\mathbf{4 . 1}$ & $<\mathbf{0 . 0 0 1} * *$ \\
\hline LEV & $\mathbf{0 . 0 8}$ & $\mathbf{0 . 1}$ & $\mathbf{0 . 0 5}$ & $\mathbf{1 . 7}$ & $\mathbf{0 . 0 8}$ \\
\hline LTG & $\mathbf{0 . 0 4}$ & $\mathbf{0 . 0 5}$ & $\mathbf{0 . 4}$ & $\mathbf{0 . 0 6}$ & $\mathbf{0 . 8 0}$ \\
\hline CBZ & $\mathbf{0 . 2 9}$ & $\mathbf{0 . 3 4}$ & $\mathbf{0 . 0 5}$ & $\mathbf{6 . 9}$ & $<0.001 * *$ \\
\hline PHT & $\mathbf{0 . 4 1}$ & $\mathbf{0 . 2 1}$ & $\mathbf{0 . 0 4}$ & $\mathbf{5 . 4 3}$ & $<0.001 * *$ \\
\hline VPA & $\mathbf{0 . 6 5}$ & $\mathbf{0 . 2 2}$ & $\mathbf{1 . 9 0}$ & $\mathbf{0 . 4 2}$ & $\mathbf{0 . 0 7}$ \\
\hline Therapy duration & $\mathbf{1 . 0 5}$ & $\mathbf{0 . 2 9}$ & $\mathbf{3 . 7 9}$ & $\mathbf{0 . 0 7}$ & $\mathbf{0 . 9 5}$ \\
\hline
\end{tabular}

SE: standard error

Fig 1:- Mean tHcy levels in epileptic patients receiving different AEDS (traditional and new) and the control group according to MTHFR genotype.

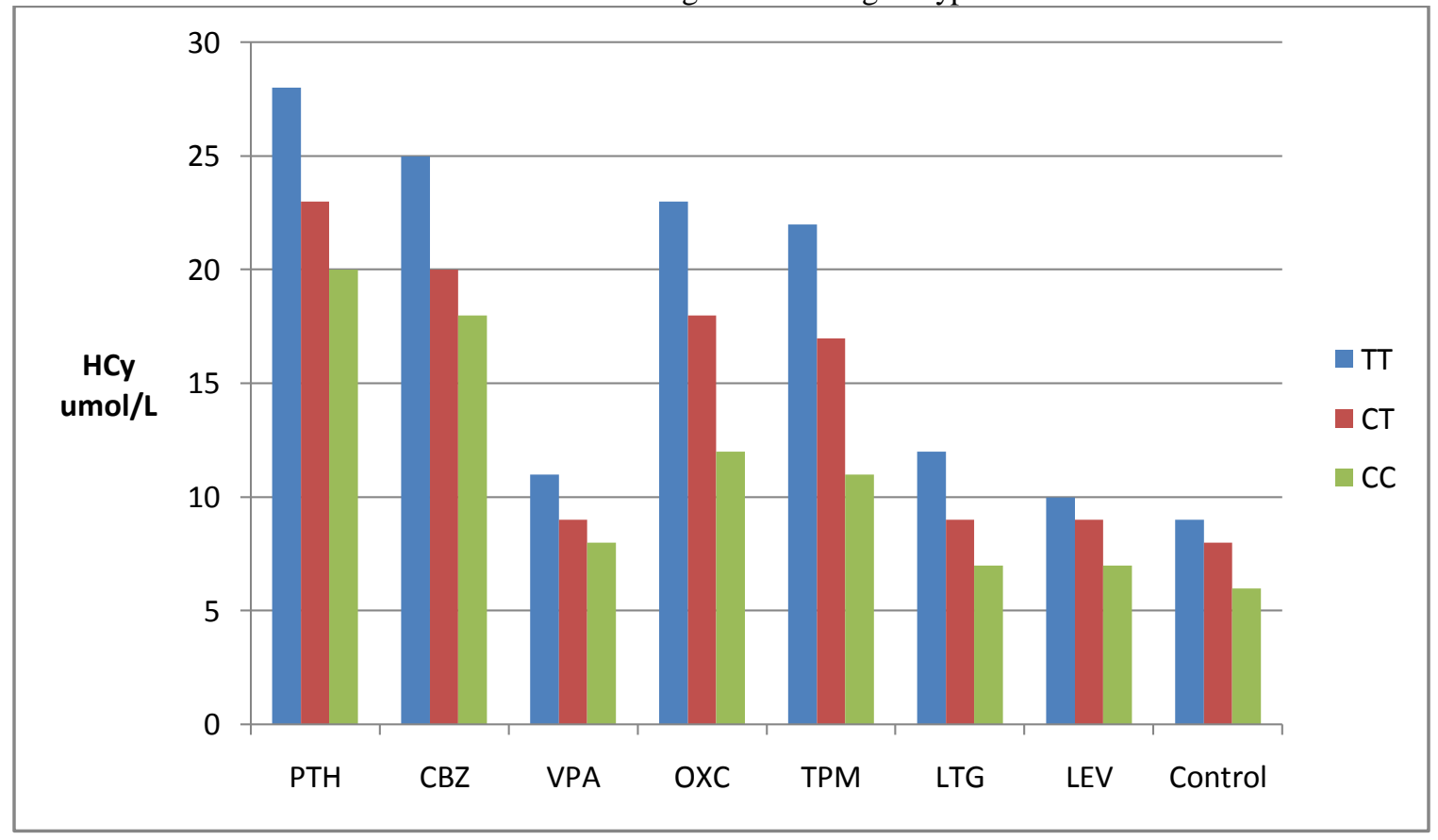

\section{Discussion:-}

The interest of the medical community in the amino acid Hcy stems from the observation that elevated plasma Hcy has been associated with cardiovascular disease in multiple large-scale epidemiologic studies and, consequently, it is considered as an independent risk factor for atherosclerosis (Humphrey et al., 2008). An additional aspect to be considered, and strictly associated to hyper-tHcy, is the AED-induced folate deficiency, a condition that itself may have different clinical implications (Reynolds, 2006; McNulty \& Scott, 2008). 
We observed a higher mean tHcy and higher prevalence of hyperhomocysteinemia in epileptic patients receiving AEDs than in the controls. The present data confirm previously published data by (Verrotti et al., 2000; Caccamo et al., 2004; Belcastro et al., 2007; Tan et al., 2009) who showed that epileptic patients on chronic AED therapy are more prone than the general population to develop hyper-tHcy and low folate levels.

An elevated plasma level of homocysteine can be induced by either genetic or environmental factors. Because MTHFR $677 \mathrm{C}--*$ T mutation is known to be associated with reduced enzyme activity and AEDs decrease MTHFR enzyme activity, we examined whether the combined presence of MTHFR $677 \mathrm{C}$-- T mutation and AEDs intake in epileptic patients causes elevated tHcy. In the population studied, the frequency of homozygosity for MTHFR 677 TT mutation in epileptic patients was higher than that in the controls. In epileptic patients receiving AEDs, hyperhomocysteinemia was more frequent in the MTHFR TT genotype versus CT or CC genotypes in agreement with Yoo et al. (1999) Ashfield et al. (2002) and Belcastro et al.(2010). This can be explained by the fact that individuals with the 677TT genotype, have approximately 30\% the MTHFR enzyme activity of those with the 677CC genotype as reported by Rozen, (1997) and Rielly et al .(2014). They also reported that low folate affects individuals with the 677TT genotype to a greater extent than those with the 677CC/CT genotypes and these results were parallel to ours. So, 677TT individuals with lower plasma folate levels are at higher risk for elevated plasma homocysteine levels than those with 677CC/CT genotype. In this context, patients carrying the 677TT genotype had a more pronounced drop in tHcy and a bigger increase in serum folate concentrations than those with the 677CC or 677CT genotype after switching from a low-folate to a high-folate diet (Silaste et al.,2001) or after supplementation with folic acid (Fohr et al.,2002).

In our patients with MTHFR TT homozygotes had a higher tHcy and lower plasma folate in the phenytoin and carbamazepine group, but not in the valproic acid group and that correlates with the findings of Yoo et al., 1999. In keeping with other studies (Ono et al ., 2002 ; Vurucu et al., 2008) duration of therapy has no clear effect on tHcy levels.

The new finding obtained from this study was that TPM and OXC among of the recent AEDs can cause hyper-tHcy as the old ones, whereas lamotrigine (LTG) and levetiracetam (LEV) are devoid of this effect. In this context, our data might have practical implications, in the case of well-controlled patients on those medications, a supplement of folate could be prescribed to normalize plasma tHcy levels which also match with previous recommendations ofHuemer et al., 2005; Reynolds, 2006; Belcastro et al., 2007.

With respect to genetic variation, a common MTHFR $677 \mathrm{C} \sim \sim \mathrm{T}$ mutation is a determinant of hyperhomocysteinemia in epileptic patients receiving anticonvulsants, suggesting that a gene-drug interaction induces hyperhomocysteinemia. Since hyper-tHcy is a modifiable risk factor for vascular disease and a sensitive marker for folate status, we suggest that epileptic patients receiving anticonvulsants should be monitored for tHcy levels.

Epileptic patients receiving AEDs may have a higher folate requirement to maintain a normal tHcy level, especially homozygotes for the MTHFR 677 TT mutation.

In the view of the previous findings, we recommend if patients are not satisfactorily controlled by PTH, CBZ, OXC and or TPM, a switch to another drug, like LTG or LEV among the new AEDs, or VPA among the older ones, could be taken into consideration, as indicated by the present data and those of other studies (Gidal et al., 2005; Mintzer et al., 2009). But if our patients are controlled and adherent to the medications which incriminated in hyperhomocysteinemia, add on folate supplementations would be helpful in normalization of its levels.

\section{Refreences:-}

1. Ono H, Sakamoto A, Mizoguchi N, Sakura N. The C677T mutation in the methylenetetrahydrofolate reductase gene contributes to hyper homocysteinemia in patients taking anticonvulsants. Brain Dev 2002;24:223-6.

2. Verrotti A, Pascarella R, Trotta D, Giuva T, Morgese G, Chiarelli F. Hyperhomocysteinemia in children treated with sodium valproate and carbamazepine.Epilepsy Res 2000;41:253-7.

3. Belcastro V, Striano P, Gorgone G, Costa C, Ciampa C, Caccamo D, et al.Hyperhomocysteinemia in epileptic patients on new antiepileptic drugs. Epilepsia2010;51:274-9.

4. Belcastro V, Gaetano G, Italiano D, Oteri G, Caccamo D, Pisani LR, et al.Antiepileptic drugs and MTHFR polymorphisms influence hyper-homocysteinemia recurrence in epileptic patients. Epilepsia2007;48:1990-4. 
5. Jacques PF, Bostom AG, Williams RR, Ellison RC, Eckfeldt JH, Rosenberg IH, et al. Relation between folate status, a common mutation in methylenetetrahydrofolate reductase, and plasma homocysteine concentrations. Circulation 1996; 93: 7-9.

6. Reynolds EH. (2006) Vitamin B12, folic acid, and the nervous system. Lancet Neurol 5:949-960.

7. Huemer M, Ausserer B, Graninger G, Hubmann M, Huemer C, Schlachter K, Tscharre A, Ulmer H, Simma B. (2005) HyperhomocysteinemiaHyperhomocysteinemia in children treated with antiepileptic drugs is normalized by folic acid supplementation. Epilepsia 46:1677-1683.

8. Yoo JH, Hong SB. A common mutation in the methylenetetrahydrofolate reductase gene is a determinant of hyperhomocysteinemia in epileptic patients receiving anticonvulsants. Metabolism 1999;48:1047-51.

9. Caccamo D, Condello S, Gorgone G, Crisafulli G, Belcastro V, Gennaro S, et al. Screening for C677T and A1298C MTHFR polymorphisms in patients with epilepsy and risk of hyperhomocysteinemia. Neuromolecular Med 2004;6: 117-26.

10. Gidal BE, Tamura T, Hammer A, Vuong A. (2005) Blood homocysteine, folate and vitamin B-12 concentrations in patients with epilepsy receiving lamotrigine or sodium valproate for initial monotherapy. Epilepsy Res 64:161-166.

11. Sener U, Zorlu Y, Karaguzel O, Ozdamar O, Coker I, Topbas M. Effects of common anti-epileptic drug monotherapy on serum levels of homocysteine, vitamin B12, folic acid and vitamin B6. Seizure 2006;15:79-85.

12. Kurul S, Unalp A, Yis, U. Homocysteine levels in epileptic children receiving antiepileptic drugs. J Child Neurol2007;22:1389-92.

13. Humphrey LL, Fu R, Rogers K, Freeman M, Helfand M. (2008) Homocysteine level and coronary heart disease incidence: a systematic review and meta-analysis. Mayo ClinProc 83:1203-1212.

14. Fohr IP, Prinz-Langenohl R, Brönstrup A. et al. 5,10-Methylenetetrahydrofolate reductase genotype determines the plasma homocysteine-lowering effect of supplementation with 5-methyltetrahydrofolate or folic acid in healthy young women. Am J ClinNutr. 2002;75:275-282. [PubMed]

15. Silaste M-L, Rantala M, Sämpi M. et al. Polymorphisms of key enzymes in homocysteine metabolism affect diet responsiveness of plasma homocysteine in healthy women. J Nutr. 2001;131:2643-2647. [PubMed]

16. Ashfield-Watt PA, Pullin CH, Whiting JM. et al. Methylenetetrahydrofolate reductase $677 \mathrm{C}>\mathrm{T}$ genotype modulates homocysteine responses to a folate-rich diet or a low-dose folic acid supplement: A randomized controlled trial. Am J ClinNutr. 2002;76:180-186.

17. Rozen R. Genetic predisposition to hyperhomocysteinemia: deficiency of methylenetetrahydrofolate reductase (MTHFR). ThrombHaemost. 1997; 78(1):523-526. [PubMed: 9198208]

18. Reilly R, McNulty H, Pentieva K, Strain JJ, Ward M (2014). "MTHFR 677TT genotype and disease risk: is there a modulating role for B-vitamins?". The Proceedings of the Nutrition Society. 73 (1): 47-56. doi:10.1017/S0029665113003613. PMID 24131523

19. Vurucu S, Demirkaya E, Kul M, Unay B, Gul D, Akin R, et al. Evaluation of the relationship between C677T variants of methylenetetrahydrofolate reductase gene and hyperhomocysteinemia in children receiving antiepileptic drug therapy. ProgNeuropsychopharmacolBiol Psychiatry 2008;1(32):844-8.

20. Myers GL, Christenson RH, Cushman M, et al: National Academy of Clinical Biochemistry Laboratory Medicine Practice guidelines: emerging biomarkers for primary prevention of cardiovascular disease. ClinChem, 2009;55(2):51-57

21. Benoist BD: Conclusions of a WHO Technical Consultation on folate and vitamin B12 deficiencies. Food and Nutrition Bulletin 2008; 29(2) :238-244 